\title{
Effect of using imagination in teaching short stories on vocabulary development of Iranian lower intermediate EFL learners
}

Mousaee, Galeh Safar

English Department, Faculty of Humanities, Najafabad Branch, Islamic Azad University, Najafabad, Isfahan, Iran (safar.mousaee@gmail.com)

Tabatabaei, Omid $\bowtie$

English Department, Faculty of Humanities, Najafabad Branch, Islamic Azad University, Najafabad, Isfahan, Iran(tabatabaei@phu.iaun.ac.ir)

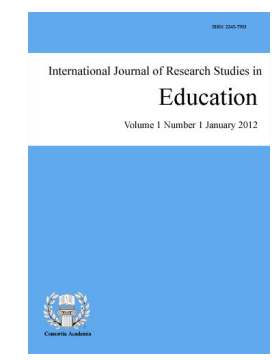

ISSN: 2243-7703 Online ISSN: 2243-7711

OPEN ACCESS

Received: 23 August $2016 \quad$ Revised: 14 October $2016 \quad$ Accepted: 16 October 2016 Available Online: 19 October $2016 \quad$ DOI: $10.5861 /$ ijrse.2016.1614

\section{Abstract}

This research was carried out to find out whether using imagination in teaching short stories is effective on Iranian EFL learners' short and long term vocabulary learning. To this end, an OPT was administered and out of 100 students 60 male students that were in the same level of proficiency were selected as the control and the experimental groups. A pretest was also administrated to check their knowledge at the beginning of the study. After that, the experimental group was taught through imagination; while the control group learned vocabulary through conventional method. There was a 3-month treatment between the pretest and the posttest. When 3 months of instruction ended, another vocabulary test, as the posttest, was administered to the participants of both groups to assess their vocabulary knowledge. Using independent samples t-tests, it was showed that using imagination was more effective than the traditional method of teaching vocabulary on the Iranian EFL learners. The obtained results also confirmed the effectiveness of using imagination on retention of vocabulary knowledge. Two weeks later, a delayed posttest was administrated in order to measure the effectiveness of using imagination on retention of vocabulary and effectiveness of using imagination was confirmed. The findings of this study offer various implications for Iran Ministry of Education, EFL curriculum makers, language schools, and university students.

Keywords: imagination; vocabulary; long-term memory; short-term memory 


\section{Effect of using imagination in teaching short stories on vocabulary development of Iranian lower intermediate EFL learners}

\section{Introduction}

Vocabulary is crucial to language and is of great significance to language learners. How we deal with vocabulary is definitely central to the process of language teaching and language learning. One thing that students, teachers, materials writers, and researchers all agree on is that vocabulary acquisition is an essential part of mastering a second language. However, the best means of achieving vocabulary learning is still unclear because it depends on a wide variety of factors (Schmitt, 2008). Reviewing some studies in the field of vocabulary teaching, it is logical to say that students do not feel interested in attending vocabulary classes because of the low level of interest, which may be due to traditional and non-innovative methods of teaching vocabulary. The low interest level in vocabulary learning requires an examination into the use of new methods of teaching vocabulary, such as the use of imagination.

Vocabulary development is a nonstop process where learners meet the words many times in their learning to increase and deepen their knowledge and their use of words in the foreign language. Word memorization is also facilitated through using meaningful activities to practice vocabulary as it provides learners with opportunities to memorize words effectively, which means that this cannot be achieved successfully if they just practice them orally by drilling or by using flashcards. Activities which involve learners in thinking about words and making decisions about them allow learners to remember words effectively (Cameron, 2001). The importance of learning vocabulary cannot be stressed enough for any student at any stage of educational growth. In the background of existing research about the importance of vocabulary development, it becomes imperative that the teaching of vocabulary be debated and the techniques used for it be evaluated from time to time.

Visualization is a skill which can help us to have a better comprehension of new vocabulary in short stories. We know that when readers lose their mental picture, comprehension is definitely lost. The role of the reader in the process of meaning construction out of the text is so crucial that Widdowson (1979) maintains that meaning does not reside in the text, but rather any text has potential for meaning. In other words, it is the reader who takes advantage of that potentiality to construct his/her own meaning out of the text and to attribute certain meanings to the text. The ability to see pictures in the mind, namely, visualizing, in the process of reading and recalling texts has been assumed to be one of the key features of the reading activity in the mother tongue, especially when one is engaged in reading a narrative or descriptive text. The point is that, as Tomlinson (1997) maintains, such texts seem to have a greater potential for engaging the mind of the typical reader than other types of reading texts. Thus, it appears that, for better understanding of such texts, readers need to turn their semantic contents into mental pictures that are, into mental images painted by the readers themselves. This study aims at investigating the effect of using imagination in teaching short stories on vocabulary development of Iranian lower intermediate learners.

\section{Literature Review}

Stevick (1986) believes that "words that have come into our heads from reading or listening commonly leave us with pictures, sounds and feelings in our minds." Similarly, Denis (1982) suggests that the reading of descriptive or narrative texts by many readers "is accompanied by a sequence of visual images that express the semantic content of the text" (p. 540). In a similar comment, Brewer (1988) maintains that descriptive and narrative texts, in particular, tend to produce imagery in the mind during reading. According to Oxford and Crookall (as cited in Abhaji Ezabadi, 2011, p. 153), "learners have better recall and appropriate use of the words when they learn them coded dually, verbally and visually, than when the words are coded in a single manner". They concluded, "Additional pictorial cues are effective and efficient in helping learners make associations 
between pictures and words".

In a study by Ghazanfari (2011) did a study with two homogenous group who were randomly assigned to experimental and the other as the control group, both studying the same short stories. The experimental group was instructed how to form pictures in the mind i.e., how to visualize before reading, while reading, and after reading a short story, for example, by being requested to draw pictures of the characters, scenes, or settings in the story as they perceived them. The control group, however, did not receive any training with respect to imagery production and was not told to practice visualization before, while, or after reading the same texts as the experimental group did. The results of a reading comprehension test on the short stories that had been discussed in both classes, and also a recall test, administered two weeks later, indicated that the "visualizers" significantly outperformed the "non-visualizers", i.e., the control group, on both tests.

According to Eghtesadi (2010), "encoding and storage are necessary to acquire and retain information, but the crucial process in remembering is retrieval or bringing information from long term memory to working (short-term) memory" (p. 43). He focuses on the role of retrieval cues which are any stimuli that help learners to recall information. He believes "the more effective retrieval cues attached to an item the better it would be recalled". Concluding, as Eghtesadi mentioned, pictures can be one of the good retrieval cues which help learners to recall the information. In addition, according to O'Keefe and Solman (1987) "It is generally considered that the content of stories read in the presence of illustrations is better comprehended, remembered, and recalled, than the same content read without the illustrations" (p. 354). It has also been indicated that "images may improve memory, as not only the word is stored, but also the image of the object" (Iglesia, Buceta, \& Campos, 2004, p. 3). According to Brown "this advantage is generally referred to as the picture superiority effect" (2007, p. 1).

The present study aimed to address the following questions:

$>\quad$ Does practice of imagination in teaching short stories have any significant impact on short term recall of new lexical items?

$>$ Does practice of imagination in teaching short stories have any significant impact on long term recall of new lexical items?

\section{Methodology}

\subsection{Participants}

The participants of the study were 100 Lower-intermediate male students studying at Sokhanpardaz language institute in Isfahan. Then, based on their performance on OPT 60 lower intermediate participants were selected. All of the participants were native speakers of Persian. Afterwards, a test of vocabulary as a pretest was administrated. Then, students were divided into two groups: experimental group containing 30 participants and control group with 30 participants.

\subsection{Instruments}

The instruments in this study were a researcher-made vocabulary test included 40 vocabulary items. The validity of the test was confirmed by two experienced teachers, and the reliability of the test was determined through KR-21.

\subsection{Procedure}

Through an OPT, 60 students were selected and then after pretest students were randomly assigned to two equal groups (each consisting of 30students), the experimental group (i.e., the imagination group, or group A. 
Mousaee, G. S., \& Tabatabaei, O.

The idea of imagination method was taken from the suggestion for further research of a study), in addition to being provided with conventional means of explaining the new words by the instructor/researcher (e.g., with regard to some lexical items, the role of the characters vis-à-vis each other, rhetorical figures, etc.) was instructed and encouraged to imagine before, whilst, and after reading the narrative text in the class. They were asked, for example, to imagine the setting, the characters, and the scenes described in the story in their minds. For instance, they were requested to, "Try and see Eveline's face in your mind." Or the researcher told the students, "As you are busy silently reading the story, as soon as you come to a description of, say, a place, a landscape, a character, a situation, an object, or whatever that can be imaginable, do your best to form a picture of that in your mind and try to imagine it as vividly as you can." The book that they studied was an English short story book known as "The Adventures of Huckleberry Finn" the difficulty level of book was lower intermediate as it was written on the book the study was based on cognitive model. The experimental group was also asked to draw some of the characters, objects or scenes depicted in the story as they imagined them in their minds in the simplest manner they could. Or they were encouraged to summarize some portions of the stories by drawing a series of related pictures. There are many students on the advantage of imagination after they leave the class, when they are by themselves at home dealing with the reading material.

The control group (group B), however, were not asked or encouraged to apply such visualization practices (for example, not being requested to form pictures related to people, objects, situations, and so on in the mind; nor being asked to draw the characters, objects, or scenes in the story, etc.) in the process of reading the stories. In other words, the control group was merely taught by applying the conventional procedures of teaching new vocabulary in literary texts (for instance, dealing with vocabulary, comprehension of some portions of the text, the role of characters in interactions with each other, etc.) and discussing figures of speech (e.g., metaphors, similes, etc.) in the same manner as these things were being discussed in the experimental class after three months instruction a posttest was administrated in order to compare the results and two weeks later a delayed posttest like posttest was administrated to measure the effectiveness of recall and retention.

\subsection{Data Analyses}

The data were collected through a pre- and post-test in order to answer the research questions. The results of both tests were analyzed using the SPSS program. First, the data of the pretest for each group was inserted and analyzed separately in order to find the mean and standard deviation of the scores of each group. The same procedure was followed for the scores of the posttest and delayed posttest of each group. An independent sample $t$-test was used and the hypothesis was tested at a .05 level of significance.

\section{Results and discussion}

To answer the first research question addressing the effectiveness of imagination on short term recall of new lexical items, a $t$-test was run between the participants' scores of the experimental and control group on pretest and posttests. The descriptive statistics of pre-test are presented in Table 1.

\section{Table 1}

Descriptive Statistics for the Participants' Performance in the English vocabulary Pretest

\begin{tabular}{lcccc}
\hline \multicolumn{1}{c}{ group } & $\mathrm{N}$ & Mean & SD & Std. Error Mean \\
\hline experimental & 30 & 19.33 & 3.45 & .63 \\
control & 30 & 19.60 & 4.02 & .73 \\
\hline
\end{tabular}

As shown in Table 1 above, the mean of control group was higher than that of the experimental group (19.60 and 19.33 respectively). To see if this difference was statistically significant or not, an independent sample $t$-test was applied. Results show that the mean difference between the two groups was not significant differences $(\mathrm{t}$ $=-.276, p>0.05$ ). This shows that the students in the two groups were at the same level of English vocabulary knowledge. The scores obtained from the immediate posttest of English vocabulary for both groups of the 
Effect of imagination in teaching short stories on vocabulary of Iranian lower intermediate EFL learners

control and the experimental were compared statistically. The means and standard deviations for the immediate posttest are presented in Table 2 .

Table 2

Descriptive Statistics for the Participants' Performance on the Immediate Posttest

\begin{tabular}{lllcc}
\hline \multicolumn{1}{c}{ group } & $\mathrm{N}$ & Mean & SD & Std. Error Mean \\
\hline experimental & 30 & 24.53 & .51 & .09 \\
control & 30 & 20.03 & 1.24 & .23 \\
\hline
\end{tabular}

As shown in Table 2 above, the mean of the experimental group was higher than that of control group (24.53 for the experimental group and 20.03 for control group). Then, an independent $t$-test was performed using SPSS to see if the possible differences between the two groups were statistically different. The result of the independent samples t-test show that there was a significant difference between the two means ( $\mathrm{t}=-18.33$, sig=.000) at the level of 0.05.Therefore, it can be concluded that participants of the experimental group improved to a greater extent due to the treatment they received. Therefore, the answer to the first research question is that using imagination has effectively improved participants' learning English vocabulary.

\subsection{The Second Research Questions}

In order to answer the second research question addressing the effectiveness of imagination on long term recall of new lexical items two paired $t$-test was administrated. The descriptive statistics are presented in Table 3.

Table 3

Descriptive Statistics for the Control Group Participants' Performance on Delayed Posttest

\begin{tabular}{llccc}
\hline & Mean & N & SD & Std. Error Mean \\
\hline Delayed posttest of control & 20.03 & 30 & .99 & .18 \\
Posttest of control & 17.57 & 30 & 1.50 & .27 \\
\hline
\end{tabular}

As shown in Table 3 above, the mean of control group posttest was higher than the delayed posttest of control group (17.57 and 20.03, respectively). In order to see whether differences were significant or not, a paired samples $t$-test was run. Results show that the value of the t-observed reveals that difference between the means was statistically significant $(\mathrm{t}=7.607$ and $\mathrm{sig}=.000)$. The results showed that the differences between control group in posttest and delayed posttest was statistically significant for delayed and immediate posttest of the control group $(p>.05)$. Therefore, the performance of the control groups' posttest was better than that of delayed posttest. It shows that the students in the delayed posttest lost their knowledge of English vocabulary they have learned to some extent.

In order to measure the effectiveness of using imagination software on students' vocabulary retention a paired sample t-test between scores of experimental students in posttest and delayed posttest was administrated. Table 4 shows the various descriptive statistics.

\section{Table 7}

The Experimental Groups' Performance on the Immediate and Delayed Posttest

\begin{tabular}{lcccc}
\hline & Mean & N & SD & Std. Error Mean \\
\hline Delayed posttest of control & 23.90 & 30 & 2.09 & .38 \\
Posttest of Experimental & 24.43 & 30 & .57 & .10 \\
\hline
\end{tabular}

According to the above table, the mean of the experimental group on posttest was higher than the delayed posttest (24.43 and 23.90, respectively).In order to see whether differences were significant or not, a paired samples $t$-test was run. Results show that there was no significant difference between the two means $(\mathrm{t}=-1.464$, $p=.154$ ) at the level of 0.05 . Therefore, it can be concluded that participants' performance of the experimental group in delayed posttest has not changed to a great extent compared to their performances in the immediate 
Mousaee, G. S., \& Tabatabaei, O.

posttest. Therefore, the answer to the second research question is that using imagination has effectively improved participants' retention of vocabulary.

\section{Discussion}

The present study aimed to examine the effect of using imagination on the short-term and long-term learning and retention of L2 vocabulary. After analyzing the data through descriptive statistics and applying a t-test on the experimental and the control groups' performance, the results revealed that the experimental groups' outperformed the control group in both learning and retention of English vocabulary. Therefore, it can be said that the training program based on imagination could have positive effects on the experimental groups' learning the vocabulary. Several studies have emphasized the role of imagination in second language learning.

\subsection{Regarding the first research question the results are consistent with following studies:}

According to Eghtesadi (2010), "encoding and storage are necessary to acquire and retain information, but the crucial process in remembering is retrieval or bringing information from long term memory to working (short-term) memory" (p. 43). He focuses on the role of retrieval cues which are any stimuli that help learners to recall information. He believes "the more effective retrieval cues attached to an item the better it would be recalled". In concluding, as Eghtesadi mentioned, pictures can be one of the good retrieval cues which help learners to recall the information. In a study by Ghazanfari, (2011) effectiveness of using visualization on reading comprehension was considered and the result was positive.

The findings of this study support the above mentioned studies. The findings of the study confirm that the experimental group's mean score was greater than that of control group due to the teaching procedures. Therefore, it can be said that the imagination-based instruction can positively affect learning English vocabulary by the Iranian EFL learners. Regarding the participants' retention of the vocabulary, students were also given a delayed posttest. The result revealed that there was a significant difference between experimental and control group. The experimental group outperformed the control group.

According to Oxford and Crookall (as cited in Abhaji Ezabadi, 2011, p. 153), "learners have better recall and appropriate use of the words when they learn them coded dually, verbally and visually, than when the words are coded in a single manner". They concluded, "Additional pictorial cues are effective and efficient in helping learners make associations between pictures and words".

\section{Conclusions}

Using imagination was shown to be an effective way to vocabulary learning compared to traditional vocabulary list memorization in short term retention. Learners absorbed target vocabulary items when they repeated them accompanied with imagination. In other words, those who learned target vocabulary items by using imagination performed better on immediate posttest in comparison with those who learned them traditionally. Also the results of the delayed posttest show that using imagination in teaching vocabulary did have significant effect on the long term retention of the vocabulary items compared to traditional ways of vocabulary learning. In fact, retention of vocabulary in control group decreased significantly in comparison with the experimental group in time interval. In addition, learners find this strategy enjoyable and helpful in EFL vocabulary learning items.

\section{References}

Abhaji Ezabadi, M. (2011). The effect of image generation on remembering story details in Iranian EFL learners. The Iranian EFL Journal, 7(2), 149-166.

Brewer, W. F. (1988). Postscript: Imagery and text genre. Text, 8, 431-438. http://dx.doi.org/10.1515/text.1.1988.8.4.431

Cameron, L. (2001). Teaching languages to young learners. Cambridge: Cambridge University Press. 
Effect of imagination in teaching short stories on vocabulary of Iranian lower intermediate EFL learners http://dx.doi.org/10.1017/CBO9780511733109

Eghtesadi, A. R., (2010). On the role of memory in learning and its implications for teachers. Foreign Language Teaching Journal, 22(84), 41-47.

Ghazanfari, M. (2011). The role of visualization in EFL learners' reading comprehension and recall of short stories. Iranian Journal of Applied Language Studies, 1(1), 1-23.

Iglesia, J. C. F., Buceta, M. J., \& Campos, A. (2004). The use of mental imagery in pair associate learning in persons with Down's syndrome. The British Journal of developmental disabilities, 50(98), 3-12. http://dx.doi.org/10.1179/096979504799104001

O'Keefe, E. J., \& Solman, R. T. (1987). The influence of illustrations on children's comprehension of written stories. Journal of Reading Behavior, 19(4), 353-377. http://dx.doi.org/10.1080/10862968709547611

Schmitt, N. (2008). Review article instructed second language vocabulary learning. Language Teaching Research, 12(3), 329-363. http://dx.doi.org/10.1177/1362168808089921

Stevick, E. (1986). Images and options in the language classroom. Cambridge: Cambridge University Press.

Tomlinson, B. (1997). The role of visualization in the reading of literature by learners of a foreign language (Unpublished doctoral thesis). University of Nottingham.

Widdowson, H. G. (1979). Explorations in applied linguistics. Oxford: Oxford University Press. 
Mousaee, G. S., \& Tabatabaei, O. 